\title{
2D seismic acquisition using different source weights integrated in the stack
}

Diogo Michelon*, Roberto B. Ribeiro, João L. Caldeira, Carlos E. Siedschlag, Frederico S. Miranda, ENEVA S.A.; Heron

Schots, CPGEO

Copyright 2019, SBGf - Sociedade Brasileira de Geofísica

This paper was prepared for presentation during the $16^{\text {th }}$ International Congress of the Brazilian Geophysical Society held in Rio de Janeiro, Brazil, 19-22 August 2019.

Contents of this paper were reviewed by the Technical Committee of the $16^{\text {th }}$ International Congress of the Brazilian Geophysical Society and do not necessarily represent any position of the SBGf, its officers or members. Electronic reproduction or storage of any part of this paper for commercial purposes without the witten consent of the Brazilian Geophysical Society is prohibited.

\section{Abstract}

Seismic imaging improvement have driven most of the efforts in the search of solutions as well as research and technology development.

Paleozoic basins are in evidence in Brazil due to the great territorial area and lack of available information. These basins have a great potential for oil and gas accumulations. The existing discoveries have been mainly developed for power generation in the last years.

Development of new technologies or techniques in the oil and gas sector usually requires high investment therefore cost reduction can be considered as a major improvement along enhance in seismic imaging quality.

In this work we will discuss the results of a 2D seismic acquisition test using multi-weight source and the quality of the data with the different source sizes. The improvement associated to the stack of all the sources sizes together is also a significant result of this test.

\section{Introduction}

ENEVA has establishing, in the private sector in Brazil, a concept of an integrated workflow based on a complete workflow from hydrocarbon exploration, production and power generation. This business model is recognized as the Reservoir to Wire (R2W) and has allowed the monetization of remote areas in the countryside of Brazil. Based on this concept an extensive exploratory campaign was done in the Parnaíba Basin. Since 2010 more than $20,000 \mathrm{~km}(12,427$ miles $)$ of $2 \mathrm{D}$ seismic were acquired, $115+$ wells drilled (exploration and development) and seven gas fields discovered. Besides this huge effort ENEVA still has and acreage of more than $42,000 \mathrm{~km}^{2}$ $(103,784,260$ ACRES). The constant quest for cost and risk reduction has leaded the exploration team to use, test and understand different technologies and solutions to minimize uncertainty.

To explore and develop an area with these proportions, 3D seismic acquisition is economically unfeasible which makes the 2D seismic data the best tool for subsurface mapping and prospect definition. The cost reduction on the latest seismic campaign allowed more seismic acquisition using the same budget, in other words, a cheaper cost per kilometer.
In this work we will discuss about a test performed trying to enhance the frequency range of the registries using a multi-weight dynamite source array. There is a good expectation of a significant improvement of the resolution of the Post Processed Seismic Data.

\section{Method}

The array used on this seismic campaign doubled the distance of the source comparing with the last one (IPT $20 \mathrm{~m}$ ), which means a significant cost reduction if the hole drilling is the most expensive stage in the onshore seismic acquisition workflow.

It has been used high sensitive single geophones with low cut frequency of $5 \mathrm{~Hz}$ per channel and a spread of 3000 20-0-20-3000 with a Shot Point Interval (SPI) of 40 meters.

The multi-weight sources used on this test were $1000 \mathrm{~g}$ $(2.2 \mathrm{lb}), 750 \mathrm{~g}(1.65 \mathrm{lb}), 500 \mathrm{~g}(1.1 \mathrm{lb}), 250 \mathrm{~g}(0.55 \mathrm{lb})$ of biodegradable dynamite, and was organized decreasing from $1000 \mathrm{~g}$ to $250 \mathrm{~g}$ in holes of 3 meters (10 feet) depth each one. This means that the redundancy of same source will be at 160 meters.

The test was performed on a real seismic along 16 kilometers and 100 units of each size of source were used, which means that each source size was tested 100 times.

The processing of the line test results on 5 different stack sections: Full Stack containing all the charge sizes with IPT of 40 meters (Figure 4), 1000g Stack with IPT of $160 \mathrm{~m}$ (Figure $3-\mathrm{A}), 750 \mathrm{~g}$ Stack with IPT of $160 \mathrm{~m}$ (Figure 3-B), $500 \mathrm{~g}$ Stack with IPT of $160 \mathrm{~m}$ (Figure 3-C) and $250 \mathrm{~g}$ Stack with IPT of $160 \mathrm{~m}$ (Figure 3-D).

Processing flow used is the standard:

- Tomographic statics correction;

- F-K filter;

- Deconvolution;

- Gain;

- Velocity analysis;

- Residual statics;

- Migration;

- Post stack filters;

\section{Examples}

The understanding about the use of different charges sizes is not new and was studied by Sharpe et al. (1944). Although the technology used on that time it was already possible to observe that larger charges provides lower frequency registration than smaller charges.

Ziolkowsk et al. (1993) and Ziolkowsk and Bokhorstt et al. (1993) discussed on theory and practice, the determination of the signature of a source using scale, and test performed was done using dynamites source of $125 \mathrm{~g}, 250 \mathrm{~g}$ and $500 \mathrm{~g}$. 
Many different papers and articles have discussing about the uses of different source sizes but all of them are comparing the quality of each source individually.

\section{Discussion of Results/Conclusions}

The array used for this case study in Parnaiba basin has shown an evolution in terms of quality and improvement. According Ziolkowski et al. (1993) the amplitude decreases in this anelastic zone by three processes: by permanent deformation of the material, by conversion of work into heat and by geometrical spreading.

The first observation during the processing the line of this test was the comparison of the energy ratio among the sources where was observed that doubling the weight do not means double of the energy:

$500 \mathrm{~g} / 250 \mathrm{~g}=125 \%$ of energy increasing

$750 \mathrm{~g} / 250 \mathrm{~g}=144 \%$ of energy increasing

$750 \mathrm{~g} / 500 \mathrm{~g}=115 \%$ of energy increasing

$1000 \mathrm{~g} / 250 \mathrm{~g}=154 \%$ of energy increasing

$1000 \mathrm{~g} / 500 \mathrm{~g}=123 \%$ of energy increasing

$1000 \mathrm{~g} / 750 \mathrm{~g}=106 \%$ of energy increasing

This cross plot of amplitude versus source weight (Figure 1) is showing that that the RMS amplitude is increasing by source size with the ratio of:

$\mathrm{A}=0.673 \sqrt[3]{W}$, where $\mathrm{W}$ is the source weight.

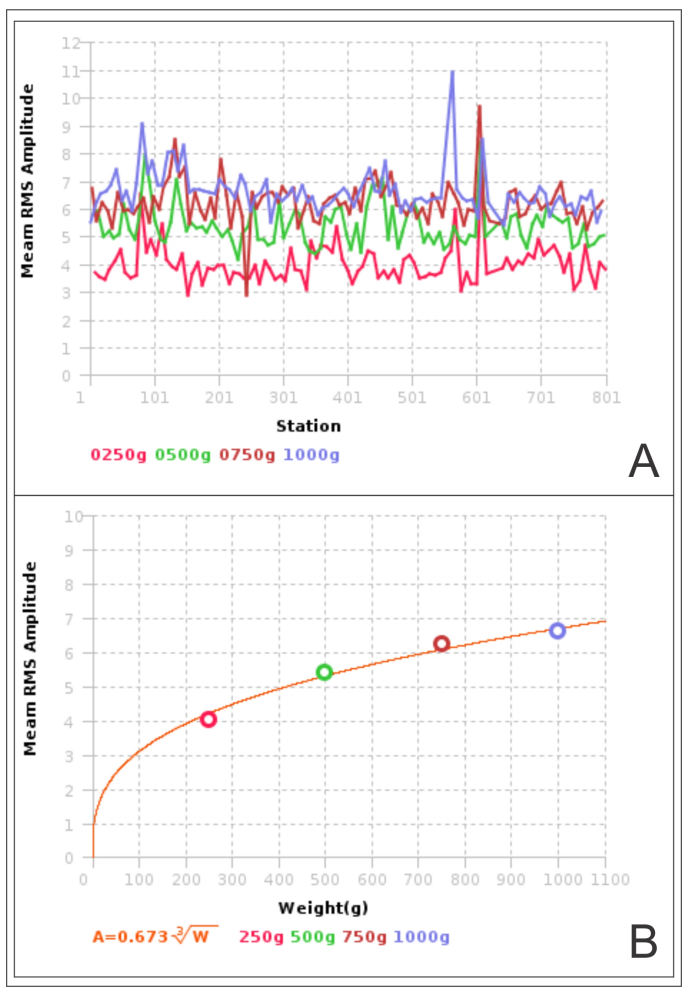

Figure 1: (A) cross plot of the RMS amplitudes by stations according different source weights. Purple color is the amplitude of $1000 \mathrm{~g}$ source, red color is the amplitude of the $750 \mathrm{~g}$ source, green color is the amplitude of the $500 \mathrm{~g}$ source and pink color is the amplitude of the $250 \mathrm{~g}$ source (B) cross plot of the RMS amplitudes by source weight and the increasing curve. The dots represents the RMS amplitude of each surce size. Purple is the $1000 \mathrm{~g}$, red is the $750 \mathrm{~g}$, green is the $500 \mathrm{~g}$ and pink is the $250 \mathrm{~g}$. The orange curve is the increasing ratio that fits all the source sizes.
The second observation is related to the frequency content (Figure 2). There is a low frequency reduction represented by the cold amplitude colors in the upper part of the section observed from largest to smallest source sizes. There is threshold in the first $10 \mathrm{~Hz}$ window for purple and dark blue amplitudes and another one in $15 \mathrm{~Hz}$ for light blue and green amplitudes related to the $1000 \mathrm{~g}$ source size (Figure 2-A). The window from $5 \mathrm{~Hz}$ to $40 \mathrm{~Hz}$ is more transitional considering the amplitude colors related to the $250 \mathrm{~g}$ (Figure 2-D) than the others source sizes. The frequency content smooth transition registered on smallest source sizes allows a more uniform frequency spectrum in the amplitude seismic section.

The third observation is related to the quality on seismic stack sections of each individual source size called Partial Stacks (Figure 3). There is a significant difference between frequency content and continuity of the reflectors located in the upper part of the sections A, B, C and D (Figure 3) up to 300ms. As observed before, as light as the source is, higher is the frequency content. The imaging quality of structure in the window from $300 \mathrm{~ms}$ to $600 \mathrm{~ms}$ on the right side of the section is better on 500g (Figure 3-C) and 250g (Figure 3-D). Although the $160 \mathrm{~m}$ of SPI of the same source sizes (Figure 3), the sections have a good imaging quality but the fold could be better reducing de SPI to $80 \mathrm{~m}$.

The fourth observation is related to the integration of all the source sizes together, called Full Stack section (Figure 4). The imaging quality in the section is also related to the fold but most important is the composition of the frequencies. Lower frequencies from the heavier weight sources and higher frequencies from the lighter weight sources results in a rich frequency spectrum observed in the section.

A good quality in a seismic section provides to the interpreter more accuracy and control for the geological framework interpretation.

As final considerations, each source size will provide different energy for different frequency and amplitude content register (Figure 1 and 2). For this basin, the lighter sources has shown a good frequency and amplitude content registration (Figure 3). The integrated source stack section (Figure 4) brought together a very good frequency and amplitude content.

\section{Acknowledgments}

I would like to thank ENEVA for the support and for providing the data used, CPGEO for the seismic processing and professor German Garabito for the supervision and revision of this work.

\section{References}

Sharpe J. A., 1944 The effect of charge size on reflection records: Geophysics, 9 no. 2, 131-142.

Ziolkowski, A. M., 1993, Determination of the signature of a dynamite source using source scaling, Part 1: Theory: Geophysics, 58, 1174-1182.

Ziolkowski, A. M., and K. N. Bokhorst, 1993, Determination of the signature of a dynamite source using source scaling, Part 2: Experiment: Geophysics, 58, 1183-1194. 


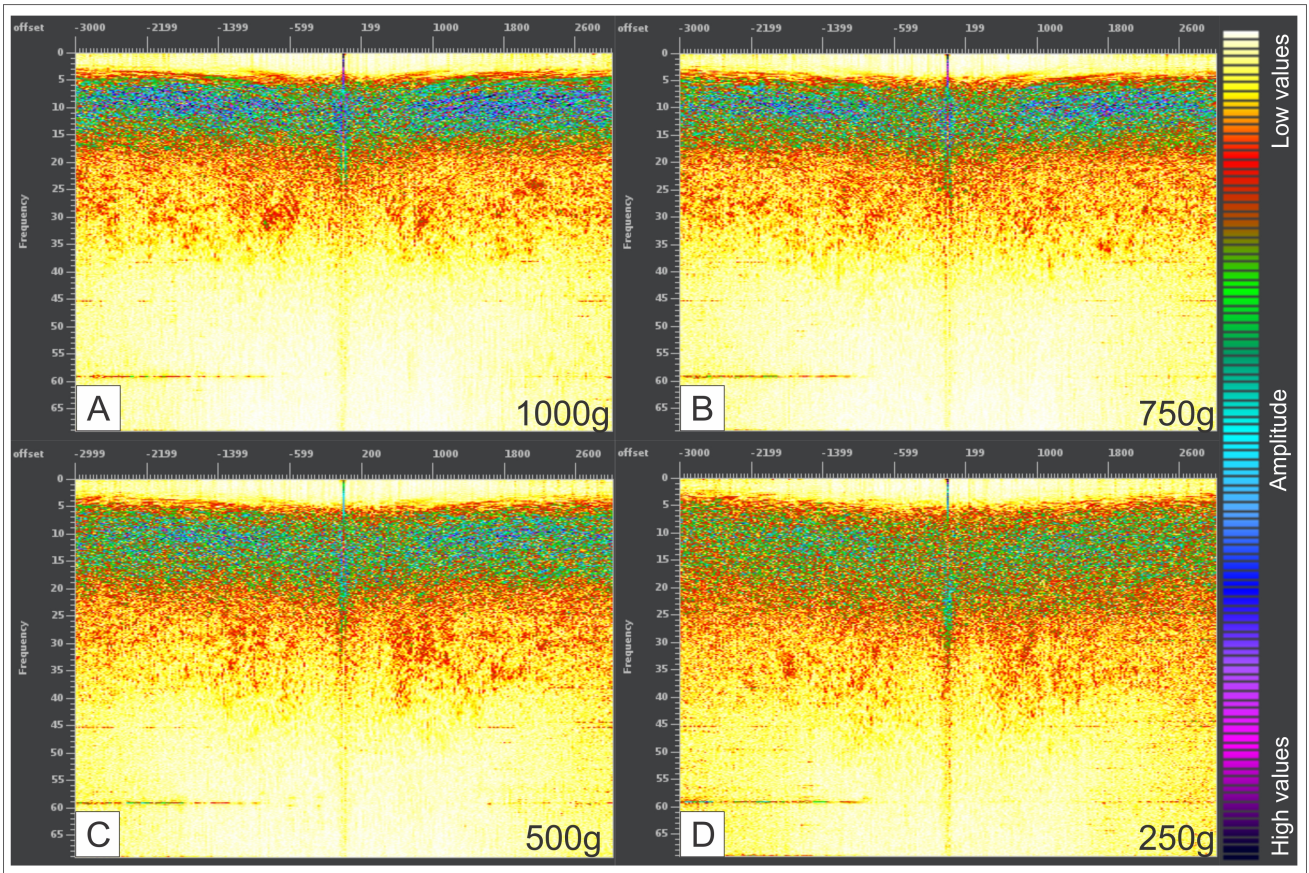

Figure 2: Cross plot of frequency by offset by amplitude values. A, B, C and D cross plots of $1000 \mathrm{~g}, 750 \mathrm{~g}, 500 \mathrm{~g}$ and $250 \mathrm{~g}$ of source weight respectively. The amplitude content along the frequency vertical axes will be transitional or blocked depending on the source size.

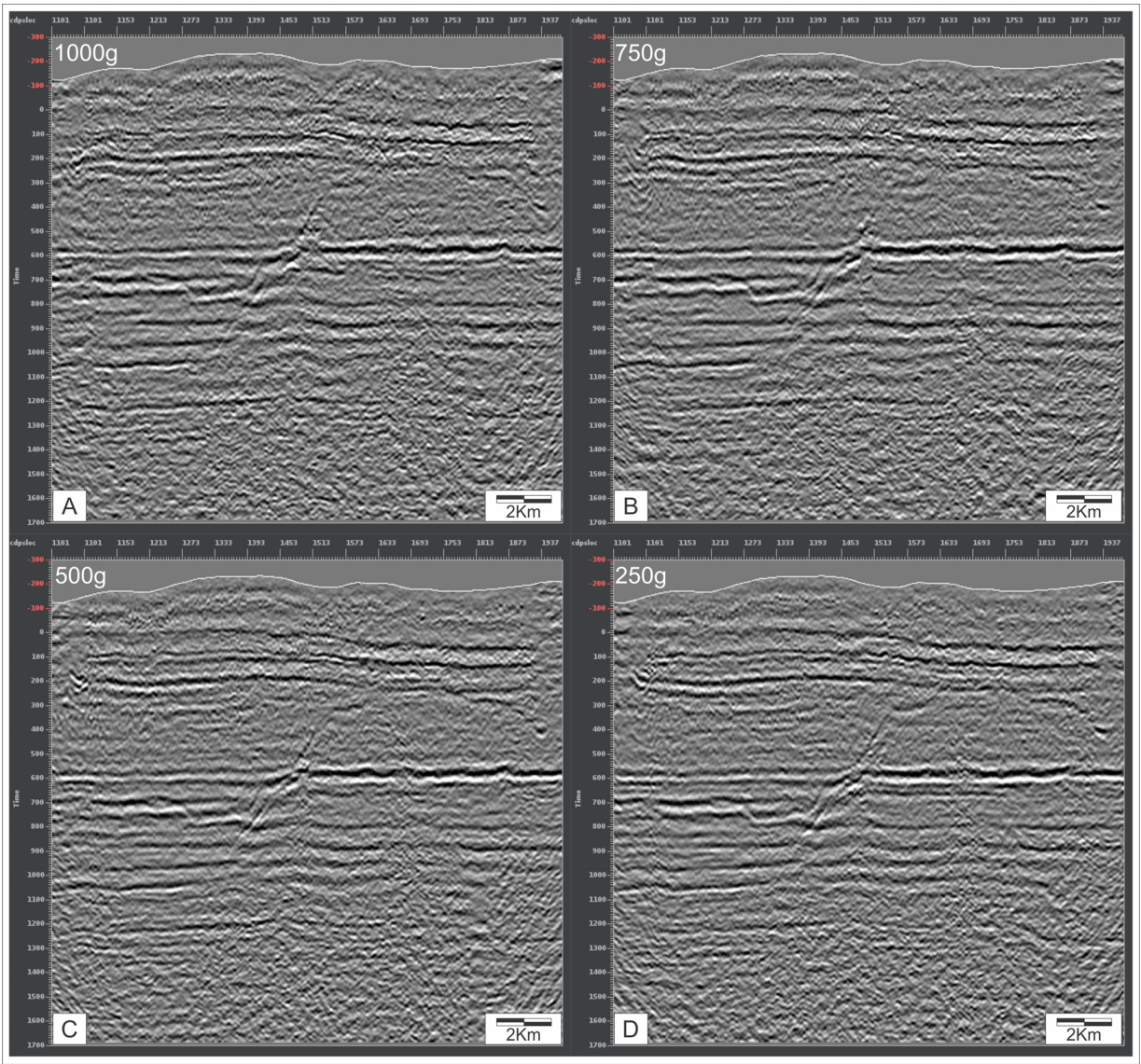

Figure 3: Partial stacks of each source size. A, B, C and D stacks of $1000 \mathrm{~g}$. $750 \mathrm{~g}, 500 \mathrm{~g}$ and $250 \mathrm{~g}$ of source weight respectively. The resolution of the structure present in the right side of the section is better on $\mathrm{C}$ and $\mathrm{D}$. The low frequency content is observed more on A and B. The high frequency content is observed more on $\mathrm{C}$ and $\mathrm{D}$. 


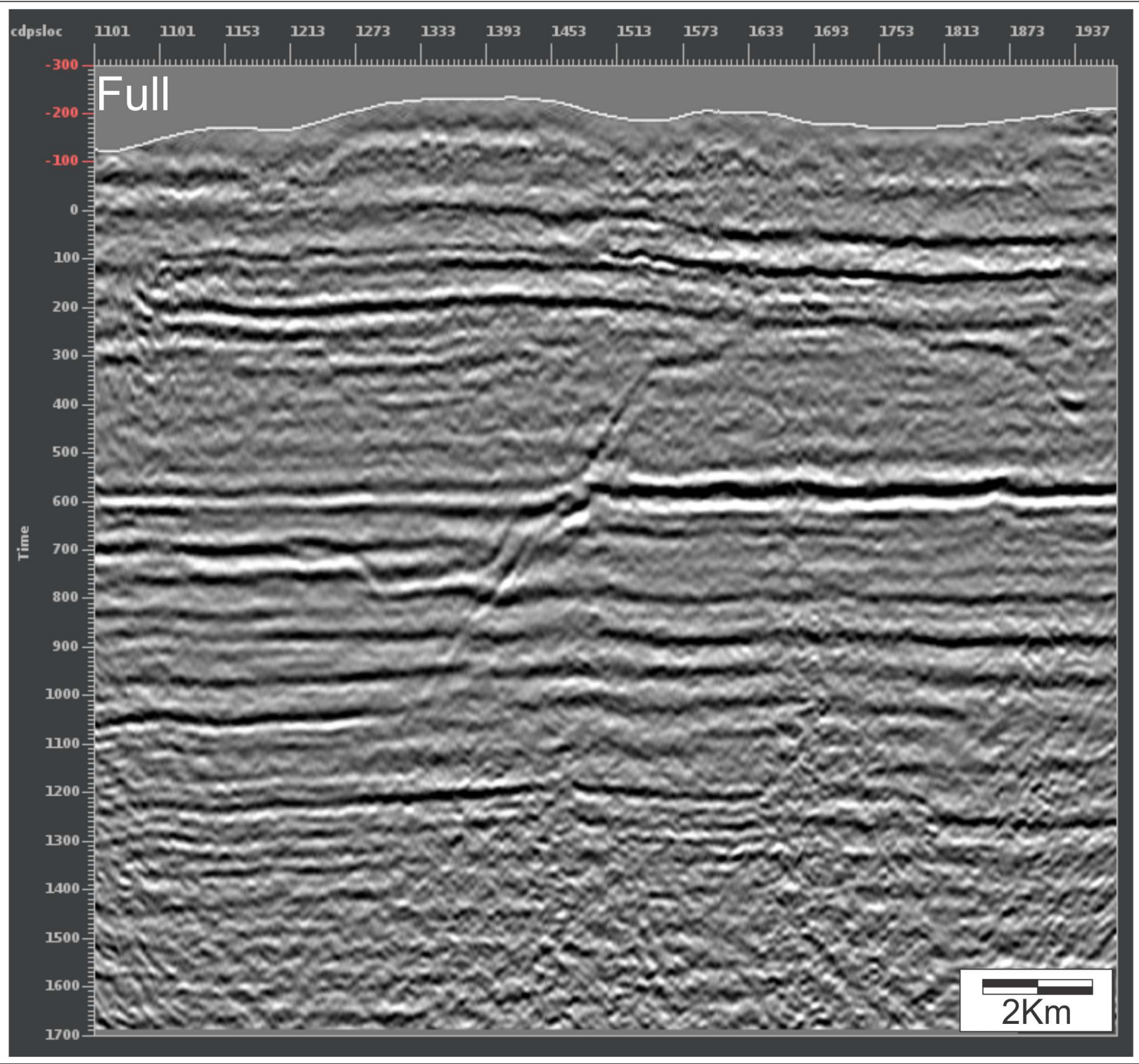

Figure 4: Full stack section of the integration of all the source weight $(1000 \mathrm{~g}, 750 \mathrm{~g}, 500 \mathrm{~g}$ and $250 \mathrm{~g})$. The resolution of the section is better than the partial stacks. 